\title{
Pembekalan Keselamatan Kerja di Atas Kapal Fiber kepada Nelayan dalam Mendukung Operasi Penangkapan Ikan di Kabupaten Tangerang
}

\section{Provision of Work Safety on Fiber Ships to Fishermen in Support of Fishing Operations in Tangerang Regency}

\author{
Izza Mahdiana Apriliani ${ }^{1 *}$, Achmad Rizal ${ }^{1}$, Pringgo KDNY Putra ${ }^{1}$, Nora Akbarsyah ${ }^{1}$, Fis Purwangka ${ }^{2}$, \\ Wazir Mawardi ${ }^{2}$, Yopi Novita ${ }^{2}$
}

* Korespondensi Penulis:

\section{Izza Mahdiana Apriliani}

\section{E-mail:}

izza.mahdiana@unpad.ac.id

${ }^{1}$ Departemen Perikanan, Fakultas Perikanan dan Ilmu Kelautan, Universitas Padjadjaran, Sumedang ${ }^{2}$ Departemen Pemanfaatan Sumberdaya Perikanan, Fakultas Perikanan dan Ilmu Kelautan, Institut Pertanian Bogor, Bogor

Submitted July 29, 2020

Revised Aug 4, 2020.

Accepted Aug 25, 2020.

\section{Abstract}

Fishing operation activities on the ship is one of the activities with a high level of risk in the world. these activities have risks that can cause losses in the material aspects to the safety of fishermen on board. Ship accidents that occur around Indonesian waters continue to increase each year. Work accidents that occur in fishing activities on ships, occur in every size and type of ship, one of which is fishing vessels that use fiber. Therefore, special knowledge and skills are needed for fishermen who use fiberglassbased vessels to carry out fishing operations. Submitting the importance of work safety on board is persuasive communication to fishermen. Based on the overall debriefing activities, both in the form of lectures and work safety discussions on fiber ships it was concluded that fishermen understood the importance of the causes of accidents at sea. As well as an increase in the skills of fishermen in working safety on fiber ships.

Keywords: cruise, FRP, self protection, ship crew, work area

\section{Abstrak}

Aktivitas operasi penangkapan ikan di atas kapal merupakan salah satu kegiatan dengan tingkat resiko yang tinggi di dunia. kegiatan tersebut memiliki resiko yang dapat memberikan kerugian pada aspek materil hingga keselamatan nelayan di atas kapal. Kecelakaan kapal yang terjadi di sekitar perairan Indonesia setiap tahunnya terus mengalami peningkatan. Kecelakaan kerja yang terjadi pada kegiatan penangakapan ikan di atas kapal, terjadi pada setiap ukuran dan jenis kapal, salah satunya adalah kapal penangkap ikan yang menggunakan bahan fiber. Oleh karena itu, dibutuhkan pengetahuan dan keterampilan khusus bagi nelayan yang menggunakan kapal berbahan fibreglass dalam melakukan operasi penangkapan ikan. Penyampaian pentingnya keselamatan kerja diatas kapal bersifat komunikasi persuasif kepada nelayan. Berdasarkan kegiatan pembekalan secara keseluruhan, baik dalam bentuk ceramah maupun diskusi keselamatan kerja di atas kapal fiber disimpulkan bahwa nelayan memahami pentingnya penyebab kecelakaan di laut. Serta adanya peningkatan skill nelayan dalam keselamatan kerja diatas kapal fiber.

Kata Kunci: ABK, area kerja, FRP, pelayaran, perlindungan diri

\section{Pendahuluan}

Aktivitas operasi penangkapan ikan di atas kapal merupakan salah satu kegiatan dengan tingkat resiko yang tinggi di dunia. Kegiatan tersebut memiliki resiko yang dapat memberikan kerugian pada aspek materil hingga keselamatan nelayan di atas kapal. Menurut Mc Guiness et al., (2013) resiko yang dihadapi oleh nelayan pada saat melakukan operasi penangkapan ikan setidaknya dapat mengakibatkan kecelakaan kerja yang berbentuk cedera ringan, cedera berat hingga kematian. Berdasarkan data FAO (2001) laju kematian nelayan memiliki jumlah 16 
kali lebih tinggi dibandingkan dengan jenis perkejaan berbahaya lainnya. Selain kecelakaan kerja, bentuk kerugian lainnya adalah seperti kerusakan dan kehilangan alat tangkap atau kapal yang digunakan (Roberts, 2004; Aasjord, 2006; Jensen et al., 2006; Anto, 2008; Jensen et al., 2014).

Kecelakaan kapal yang terjadi di sekitar perairan Indonesia setiap tahunnya terus mengalami peningkatan. Berdasarkan pada data yang dihimpun oleh KNKT (2016) telah terjadi 54 jumlah kecelakaan yang telah menelan 337 korban meninggal dunia/hilang dan 474 korban cedera. Penyebab kecelakaan di atas kapal terjadi karena melibatkan beberapa faktor yang kompleks, yaitu human factor, machines, dan environmental. Terjadinya sebuah kecelakaan timbul karena salah satu dari faktor tersebut tidak berfungsi dengan baik (Lincoln, 2002). Menurut Alimina et al., (2014) berdasarkan pada aspek teknis, kecelakaan kerja di atas kapal penangkap ikan mayoritas diakibatkan karena kelalaian dalam pemeliharaan kapal, kurangnya peralatan keselamatan dan komunikasi di atas kapal, faktor cuaca, kelailaian dalam peletakan alat tangkap di atas kapal dan kurangnya perlindungan pada anggota tubuh. Selain itu, faktor minimnya pengetahuan dan kompetensi mengenai keselamatan kerja di atas kapal pada nelayan juga merupakan salah satu faktor yang memicu terjadinya kecelakaan kerja (Santara et al., 2014; Putra et al., 2017).

Kecelakaan kerja yang terjadi pada kegiatan penangakapan ikan di atas kapal, terjadi pada setiap ukuran dan jenis kapal, salah satunya adalah kapal penangkap ikan yang menggunakan bahan fiber. Penggunaan bahan fiber sebagai bahan baku pembangunan kapal penangkapan ikan adalah salah satu alternatif akibat kelangkaan dan mahalnya ketersediaan bahan baku kayu. Selain itu, material fiber juga mudah didapatkan di dalam negeri, memiliki harga yang lebih murah dibandingkan dengan kayu, dan membutuhkan peralatan yang cukup sederhana dalam pembangunannya (Anadi et al., 2012). Namun, bahan fiber sendiri memiliki karakteristik yang mudah terbakar dan tidak cukup kuat apabila bergesakan dengan peralatan penangkapan atau kapal lainnya (Yuwandana et al., 2013). Oleh karena itu, dibutuhkan pengetahuan dan keterampilan khusus bagi nelayan yang menggunakan kapal berbahan fibreglass dalam melakukan operasi penangkapan ikan.

\section{Materi dan Metode Pelaksanaan}

Ruang lingkup materi yang disampaikan berupa penyebab kecelakaan kapal di laut dan upaya pencegahan dalam keselamatan kerja nelayan atau awak buah kapal (ABK). Adanya pemberihan materi/informasi yang dilakukan pada nelayan Kabupaten Tangerang merupakan salah satu cara untuk memberitahukan kepada nelayan mengenai pentingnya keselamatan kerja diatas kapal khususnya kapal fiber. Nelayan dapat lebih mengenal penyebab kecelakaan diatas kapal serta pencegahan yang diperlukan untuk menghindari kecelakaan tersebut.

Penyampaian pentingnya keselamatan kerja diatas kapal bersifat komunikasi persuasif. Komunikasi persuasif adalah bentuk komunikasi yang dilakukan oleh seseorang maupun kelompok sebagai komunikator terhadap orang lain atau kelompok lain sebagai komunikan yang bertujuan untuk mengubah sikap dan perilaku dengan mengoptimalkan fungsi psikologis maupun sosiologis yang terdapat dalam diri komunikan (Nida 2014). Hal ini artinya bahwa mengajak nelayan dalam mengantisipasi kecelakaan di laut khususnya dalam pengoperasian menggunakan kapal fiber. Kapal berbahan fiber saat ini sudah mulai banyak beroperasi di Indonesia karena penawaran bahan baku kayu yang semakin mahal, sehingga pembuatan kapal mulai beralih menggunakan fiber. Oleh karena itu keterampilan nelayan dalam mengoperasikan kapal fiber perlu ditingkatkan untuk menghindari kecelakaan diatas kapal.

Kegiatan dilaksanakan selama bulan Februari - Maret 2018 di Kabupaten Tangerang bekerjasama dengan Dinas Kelautan dan Perikanan Kabupaten Tangerang. Pelaksanaan kegiatan pembekalan keselamatan kerja di atas kapal fiber kepada nelayan dalam mendukung operasi penangkapan ikan dilakukan secara 3 tahap. Tahap pertama berupa inisiasi dan sosialisasi kepada khalayak sasaran. Tahap ini berupa inisiasi kepada dinas setempat dan menginventarisir kebutuhan nelayan di Kabupaten Tangerang, sehingga kegiatan ini tepat sasaran berdasarkan kebutuhan. Selanjutnya dilakukan sosialisasi kepada khalayak sasaran. Khalayak sasaran kegiatan ini adalah nelayan/ABK yang menggunakan kapal fiber dalam operasi penangkapan ikan di Kabupaten Tangerang.

Tahap kedua yaitu pelaksanaan pembekalan infromasi keselamatan diatas kapal fiber kepada nelayan dengan metode ceramah dan diskusi. 
Nelayan akan memperoleh pengetahuan melalui pembekalan informasi mengenai (1) penyebab kecelakaan kapal di laut dan (2) upaya pencegahan dalam keselamatan kerja diatas kapal fiber. Harapannya dari kegiatan ini dapat membawa perubahan meliputi pengetahuan (knowledge), cara berfikir (thinking), meningkatkan kecakapan (skill) dan sikap dalam mengoperasikan kapal fiber.

Tahapan ketiga yaitu tahap evaluasi kegiatan yang telah dilaksanakan kepada nelayan yang mencakup materi. Evaluasi dilakukan untuk mengetahui tingkat keberhasilan kegiatan dan dampaknya terhadap pola piker nelayan. Penilaian pada tahap ini dilakukan dengan diskusi dan pemantauan selama kegiatan berlangsung.

\section{Hasil dan Pembahasan}

Tahap sosialisasi dan inisisasi merupakan tahap awal dalam pelaksanaan kegiatan ini. Tahap inisiasi disambut baik oleh Dinas Kelautan dan Perikanan Kabupaten Tangerang dengan mendukung dan mengijinkan untuk pelaksanaan kegiatan ini. Bentuk dukungan dari pihak Dinas setempat yaitu dengan memfasilitasi rangkaian kegiatan dalam bentuk program kerja Dinas Kelautan dan Perikanan (DKP) Kabupaten Tangerang. Hal ini menunjukkan bahwa kepedulian DKP setempat terhadap keselamatan nelayan di Kabupaten Tangerang. Selain itu, DKP membantu menghubungkan dengan perwakilan nelayan setempat untuk diberikan sosialisasi mengenai kegiatan ini.

Tapahan sosialisasi dalam kegiatan ini merupakan audensi dengan khalayak sasaran yaitu nelayan yang menggunakan kapal fiber dalam operasi penangkapan ikan. Melalui beberapa perwakilannya, nelayan tersebut nantinya akan membagi sejumlah nelayan dalam beberapa rangkaian materi lainnya yang ada pada Program DKP Kabupaten Tangerang. Nelayan diinformasikan bahwa kegiatan akan dimulai sesuai dengan waktu yang telah ditentukan dan meminta nelayan untuk hadir tepat waktu. Pertemuan sosialisasi dengan perwakilan nelayan diantaranya membahas tahapan-tahapan kegiatan baik terkait dengan waktu serta cakupan materi kegiatan.

Pembukaan pelaksanaan pembekalan infromasi keselamatan diatas kapal fiber di pimpin oleh Kepala Bidang Perikanan Tangkap DKP Kabupaten Tangerang yang menyambut baik kegiatan kolaborasi yang dilakukan oleh perguruan tinggi bersama dengan Dinas setempat. Nelayan yang hadir dalam pembekalan mencapai 45 peserta. Pembekalan diawali dengan pre test kepada nelayan menganai pengetahuan keselamatan kerja di laut. Pre test digunakan sebagai base line indikator sebelum khalayak sasaran mendapatkan pembekalan tersebut. Indikator ini merupakan dasar penilaian sejauh mana nelayan mengetahui dan paham mengenai kecelakaan dan upaya keselamatan kerja di laut dengan menggunakan kapal fiber. Hasil pre test menunjukkan bahwa hanya $30 \%$ dari seluruh peserta yang paham mengenai keselamatan kerja di laut. Bahkan masih banyak yang melakukan aktivitas yang membahayakan nelayan ketika pengoperasian alat tangkap diantaranya yaitu aktif merokok di area mesin kapal.

Pembekalan ini dimulai dengan penyampaian materi penyebab kecelakaan kerja di laut serta upaya pencegahan dalam keselamatan kerja diatas kapal fiber. Teknik pembekalan dengan metode ceramah atau seminar merupakan proses introduksi pengetahuan dari pemberi ceramah kepada khalayak sasaran (Apriliani et al. 2017). Pengetahuan yang disampaikan dalam kasus ini adalah berbagai penyebab terjadinya kecelakaan di laut serta upaya pencegahan untuk meningkatkan keselamatan kerja di laut dalam pengoperasian kapal fiber. Pemberi ceramah adalah tim pengabdian masyarakat kolaborasi dari Institut Pertanian Bogor beserta Universitas Padjadjaran. Khalayak sasarannya merupakan nelayan/ABK yang selama ini melakukan operasi penangkapan ikan dengan dukungan kapal fiber di Kabupaten Tangerang.

Kegiatan pembekalan diikuti oleh 45 orang yang dinilai aktif dalam pelaksanaan kegiatan. Keaktifan peserta dinilai dari diskusi yang berjalan dua arah antara pemateri dan khalayak sasaran. Suasana saat penyampaian materi berlangsung dalam suasana keakraban dan kekeluargaan. Bahasa yang digunakan dalam penyampaian materi menggunakan bahasa yang santai agar khalayak sasaran dapat lebih memahami materi. Pemateri juga sesekali menggunakan Bahasa Jawa yang sering digunakan oleh nelayan sehari-hari. Selain itu katakata jenaka pun sering kali dilontarkan untuk menghangatkan suasana. Penggunaan kedua bahasa ini dimaksudkan agar pesan yang akan disampaikan lebih dipahami oleh nelayan.

Akhir dari kegiatan penyampaian pembekalan ini yaitu diskusi. Diskusi dimaksudkan untuk lebih mempertajam pesan yang telah disampaikan saat ceramah/penmbekalan materi. Berbagai pertanyaan 
dan pendapat dilontarkan oleh para peserta sehingga suasana pertemuan terasa akrab dan semangat. Banyaknya pertanyaan dan lontaran pendapat tersebut menunjukkan bahwa materi yang disampaikan dapat dikatakan telah tersampaikan kepada objek sasasaran dengan baik. Selain itu, peserta juga menyampaikan beberapa inovasi yang menarik dalam upaya pencegahan kecelakaan diatas kapal.

Secara umum kegiatan pembekalan keselamatan kerja di laut dengan menggunakan kapal fiber kepada nelayan Kabupaten Tangerang berjalan dengan lancar. Berdasarkan Tabel 1 menunjukkan perubahan sudut pandang nelayan mengenai penyebab kecelakaan di laut beserta upaya keselamatan kerja diatas kapal fiber.

Berdasarkan Tabel 1 menunjukkan bahwa indikator pencapaian yang ditetapkan oleh tim pelaksana telah tercapai setelah dilaksanakan kegiatan pembekalan ini. Pembekalan ini juga dilengkapi dengan post test untuk melihat sejauh mana pemahaman dan keterampilan peserta dalam pembekalan ini. Sejumlah 93\% peserta menyatakan bahwa peserta paham mengenai penyebab kecelakaan serta terampil dalam upaya pencegahan kecelakaan dengan memahami standar keselamatan diatas kapal fiber. Kegiatan pembekalan ditunjukkan pada Gambar 1.
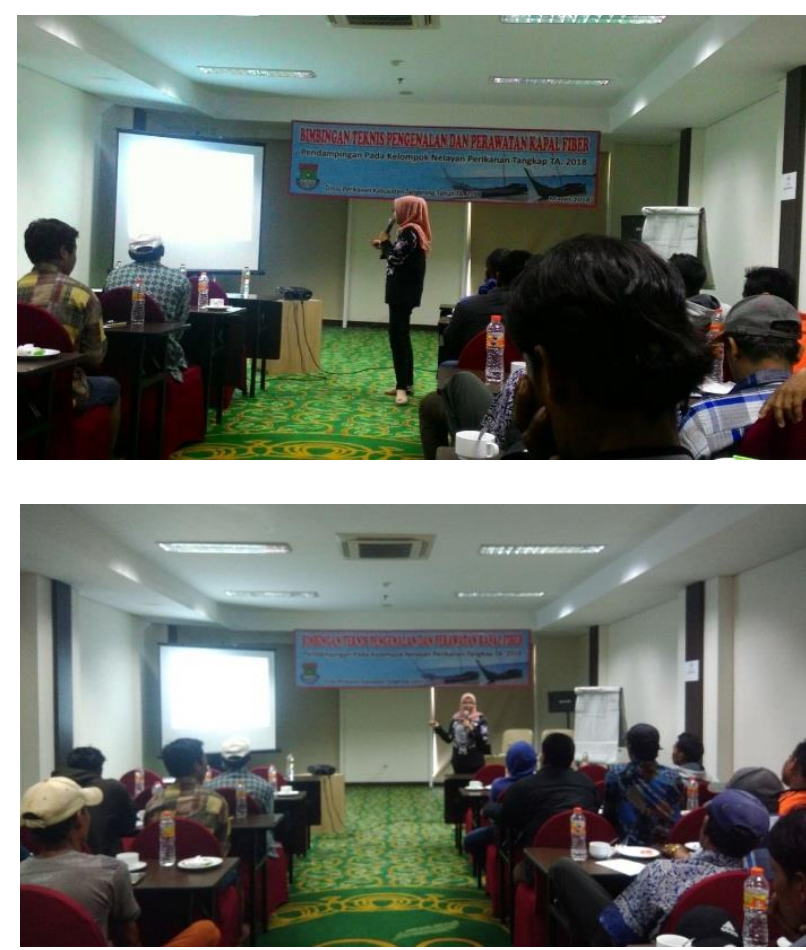

Gambar 1 Dokumentasi Pembekalan Keselamatan Kerja kepada Nelayan Kabupaten Tangerang

Tabel 1 Indikator pelaksanaan program

\begin{tabular}{|c|c|c|c|}
\hline No. & Indikator pencapaian & $\begin{array}{c}\text { Base line } \\
\text { (Sebelum kegiatan) }\end{array}$ & $\begin{array}{c}\text { Pencapaian setelah } \\
\text { kegiatan }\end{array}$ \\
\hline
\end{tabular}

1. Pemahaman mengenai penyebab kecelakaan kapal

di laut:

a. Tingkat pengetahuan nelayan tentang kecelakaan di laut skala Nasional dan Internasional

b. Tingkat pengetahuan nelayan mengenai penyebab kecelakaan di kapal khususnya kapal fiber

c. Tingkat pengetahuan nelayan tentang potensi kecelakaan di kapal fiber

2. Pemahaman keselamatan kerja di atas kapal fiber dalam operasi penangkapan ikan :

a. Tingkat pengetahuan pentingnya keselamatan kerja

b. Tingkat pengetahuan dan skills jenis keselamatan kerja diatas kapal fiber

c. Tingkat keterampilan upaya keselamatan di atas kapal fiber
- Belum mengetahui - Paham

- Sebagian belum - Paham mengetahui

- Sebagian belum - Paham mengetahui

- Sudah mengetahui - Paham

- Sebagian belum - Terampil mengetahui

- Belum mengetahui - Terampil 


\section{Kesimpulan}

Berdasarkan kegiatan pembekalan secara keseluruhan, baik dalam bentuk ceramah maupun diskusi keselamatan kerja di atas kapal fiber disimpulkan bahwa nelayan memahami pentingnya penyebab kecelakaan di laut. Serta adanya peningkatan skill nelayan dalam keselamatan kerja diatas kapal fiber.

\section{Ucapan Terimakasih}

Penulis mengucapkan terima kasih kepada Dinas Kelautan dan Perikanan Kabupaten Tangerang yang telah memberikan dana hibah dalam Bimbingan Teknis Pengenalan dan Perawatan Kapal FRP tahun anggaran 2018. Ucapan terimakasih juga disampaikan kepada nelayan Kabupaten Tangerang yang mengoperasikan kapal fiber pada aktivitas penangkapan ikan yang telah antusias dalam pelaksanaan kegiatan ini sehingga kegiatan ini berjalan dengan baik.

\section{Daftar Pustaka}

[FAO] Food and Agriculture Organization of the United Nations. 2001. Safety at Sea as Integral Part of Fisheries Management. Roma: FAO.

[KNKT] Komite Nasional Keselamatan Transportasi. 2016. Data Investigasi Kecelakaan Pelayaran Tahun 2010 - 2016. Media Release KNKT: Jakarta.

Aasjord. H.L. 2006. Tools for improving safety management in The Norwegian fishing fleet occupational accidents analysis period of 19982006. Internat. Marit. Health. (57): 1-4.

Alimina. N., Wiryawan. B., Monintja. D.R., Nurani. T.W., Taurusman. A.A. 2014. Cedera dan praktek keselamatan kerja pada perikanan tuna skala kecil di perairan selatan Sulawesi Tenggara. Prosiding Simposium Nasional Pengelolaan Perikanan Tuna Berkelanjutan, Bali, 10-11 Desember 2014.

Anadi. L., Iskandar. B.H., Monintja. D.R., Baskoro. M. S. 2012. Pengembangan desain kapal pancing tonda dengan material fibreglass di Kabupaten Buton Sulawesi Tenggara. Buletin PSP. 20(1):7180.

Antao P, Almeida T, Jacinto C, Soares CG. 2008. Causes of Occupational Accidents in the Fishing Sector in Portugal. Safety Science (46): 885-899.
Apriliani IM, Purba NP, Dewanti LP, Herawati H, Faizal I. 2017. Aksi Bersih Pantai dalam Rangka Penanggulangan Pencemaran Pesisir di Pantai Pangandaran. Jurnal Pengabdian Kepada Masyarakat 1 (2): 77-80.

Imron. M., Nurkayah. R., Purwangka. F., 2017. Pengetahuan dan keterampilan nelayan tentang keselamatan kerja di PPP Muncar Banyuwangi. ALBACORE. 1(1):99-109.

Jensen OC, Petursdottir G, Holmen IM, Abrahamsen A, Lincoln J. 2014. A Review of Fatal Accidence Rate Trends in Fishing. Int Marit Health (65): 47-52.

Jensen OC, Stage S, Noer P. 2006. Injury and Time Studies of Working Processes in Fishing. Safety Scince (44): 349-358.

McGuiness E, Aasjord HL, Utne IB, Holmen IM. 2013. Injuries in the Commercial Fishing Fleet of Norway 2000-2011. Safety Science (57): 82-99.

Nida FLK. 2014. Persuasi Dalam Media Komunikasi Massa. Jurnal Komunikasi Penyiaran Islam 2 (2): 77-95.

Nida FLK. 2014. Persuasi Dalam Media Komunikasi Massa. Jurnal Komunikasi Penyiaran Islam 2 (2): 77-95.

Putra. R.S., Purwangka. F., Iskandar. B.H. 2017. Pengelolaan keselamatan kerja nelayan di PPI Batukaras Kabupaten Pangandaran. ALBACORE. 1(1):37-46.

Roberts SE. 2004. Occupational Mortality in British Commercial Fishing, 1976-95. Occup Environ Med (61): 16-23.

Santara. A.G., Purwangka. F., Iskandar. B.H. 2014. Peralatan keselamatan kerja pada perahu slerek di PPN Pengambengan Kabupaten Jembrana Bali. Jurnal IPTEKS PSP. 1(1):53-68.

Yuwandana. D.P., Purwangka. F., Iskandar. B.H. 2013. Desain dan konstruksi perahu katamaran fiberglass untuk wisata pancing. BULETIN PSP. 21(1):119136. 